\title{
Pharmacist's Intervention on Pill Burden Effects on the Health-Related Quality of Life of Elderly Diabetic Patients in a Tertiary Hospital in Southwestern Nigeria
}

\author{
Winifred Aitalegbe Ojieabu \\ Department of Clinical Pharmacy and Biopharmacy, Olabisi Onabanjo University, Sagamu Campus, \\ Ogun State, Nigeria
}

\section{Keywords}

Pharmacist · Intervention · Pill burden · Health-related quality of life $\cdot$ Elderly diabetic patients

\begin{abstract}
Background: Diabetes and its associated complications take a toll on the elderly. It is known that medication burden could reduce patients' adherence, which in turn impacts negatively on the health-related quality of life (HRQOL) of those suffering from chronic diseases. Studies have been conducted on HRQOL and its associated factors among diabetic patients but none has studied pill burden effects on HRQOL. This research evaluated pharmacist's intervention on pill burden effects on the HRQOL of elderly diabetic patients. Methods: This 8-month randomized controlled study involved 170 elderly type 2 diabetic patients. Socio-demographics, the impact of the number and dosage frequency of drugs on adherence, and the influence of the pill burden on HRQOL scores were evaluated at baseline and at 4 and 8 months. Patients in the intervention group were educated about diabetes and its management and counselled on treatment adherence. Brisk walking was specially demonstrated to them at least 4 times during the study period. The control group received only the usual call reminders for appointment days. Results: At baseline, 58.8 and 64.7\%, re-
\end{abstract}

\begin{tabular}{ll}
\hline KARGER & ( 2019 The Author(s) Karger \\
& Published by S. Karger AG, Basel Open access \\
E-Mail karger@karger.com & This article is licensed under the Creative Commons Attribution- \\
www.karger.com/ijd & $\begin{array}{l}\text { NonCommercial-NoDerivatives 4.0 International License (CC BY- } \\
\text { NC-ND) (http://www.karger.com/Services/OpenAccessLicense). } \\
\text { Usage and distribution for commercial purposes as well as any dis- } \\
\text { tribution of modified material requires written permission. }\end{array}$
\end{tabular}

spectively, in the control and intervention groups responded "yes" (indicating a negative effect on their adherence) to $>5$ pills per prescription, while the figures were 55.3 and $15.3 \%$, respectively, at 8 months $(p=0.711$ and $p=0.000$, respectively). Patients on $1-5$ pills per prescription in the control group had the following physical functioning scores: baseline $(44.2 \pm 14.2)$ versus 4 months $(47.2 \pm 19.1)$ and 8 months $(47.7 \pm 16.1) ; p=0.277$ and $p=0.160$. The physical functioning scores in the intervention group were: baseline $(41.7 \pm 16.1)$ versus 4 months $(67.6 \pm 23.1)$ and 8 months $(92.5 \pm 3.5) ; p \leq 0.001$. The same pattern of results was found for those on $>5$ pills per prescription. Conclusion: This study demonstrates pharmacists' ability to improve the HRQOL of patients through continuous counselling, supply of relevant information, and monitoring of drug, exercise, and diet adherence. Intervention such as this could be beneficial to diabetic patients and others with chronic diseases.

$$
\begin{aligned}
& \text { ๑) } 2019 \text { The Author(s) } \\
& \text { Published by S. Karger AG, Basel }
\end{aligned}
$$

\section{Introduction}

In 2017 the International Diabetes Federation estimated the world population living with diabetes at 425 million, with Nigeria accounting for 1.7 million of those cases. The 
estimate, which covers individuals aged $20-79$ years, is projected to become 629 million by 2045 [1]. Diabetes results in increased mortality, a lower functional status, and a high risk of hospital admission [2]. The mortality and complication rates arising from diabetes are highest among older adults as compared to young diabetic individuals. Diabetes and its associated complications take a toll on the elderly, which could result in a reduced health related quality of life (HRQOL) among the sufferers $[3,4]$. This could be due to patients' inability to follow professional instructions in all aspects of its management. Earlier studies $[5,6]$ have found all HRQOL domains of type 2 diabetes to be impaired by the disease, while others $[3,7]$ have shown a strong negative impact on the social relationships and overall HRQOL of diabetic patients due to long-term complications of microvascular and macrovascular issues.

Diabetes treatment is generally difficult in the elderly due to the frail nature and other likely comorbidities of such patients. Another study [8] stated that some cognitive disorders, risk of hypoglycemia, and high rates of comorbidities could result in polypharmacy among elderly diabetic patients. Previous results [9] have established that medication burden is high among type 2 diabetes patients as some have been found to take as many as $4-10$ drugs daily. Among individuals with diabetes in America, 50\% said they take up to 7 or more medications a day and many pay out of pocket [10]. A high medication burden could lead to a reduced or lack of adherence $[11,12]$ which in turn could result into a poor quality of life for those suffering from chronic diseases. Studies $[3,7]$ have supported the evidence that good management improves the immediate as well as the longterm HRQOL of patients with type 2 diabetes. Therefore, assessing HRQOL is a component of a good management of the disease and a way to evaluate the patient's ability to managing his or her disease and its effects on his or her life.

To the author's knowledge, many studies have been carried out on HRQOL and its associated factors among diabetic patients but none has studied pill burden effects and intervention to ameliorate its effects on patients. Due to the paucity of information in this regard, especially in Nigeria, this research was conducted with the main objective of investigating pharmacists' intervention on pill burden effects on the HRQOL of diabetic patients in a teaching hospital in Nigeria.

\section{Materials and Methods}

This 8-month follow up randomized controlled study involving 170 elderly type 2 diabetic patients was carried out at the diabetic clinic of Olabisi Onabanjo University Teaching Hospital in
Sagamu, Ogun State, Nigeria. This is a state government-owned tertiary hospital. The objective of this research was explained to the participants, and those who volunteered to participate signed a consent form. The patients who met the inclusion criteria were randomly assigned to control and intervention groups (85 patients each). Age was taken as 50 years and above as stated in the WHO definition of old or older persons [13].

\section{Collection of Patients' Data}

Patients were assured of their anonymity and confidentiality of responses. Once enrolled, each patient was assigned a number, and socio-demographic variables were collected with a patient structured data format at baseline. Then, patients were scheduled to meet the researcher pharmacist every 2 months (depending on their appointment period). Information on the impact of the number and dosage frequency of drugs on adherence was collected using a questionnaire, while the pill burden effect on HRQOL was measured using RAND 36-Item Health Survey questionnaire [14]. All data were obtained at baseline and at 4 and 8 months. Patients who did not understand English were attended to by 2 research assistants through appropriate language translation. No interventions were made prior to the first administered questionnaire and this served as the baseline study with which the subsequent results were compared.

\section{Intervention}

The intervention group was educated on diabetes and hypertension, prevention, risk factors, hyperglycemia, and hypoglycemia, including pharmacological and non-pharmacological management. Patients were also counselled on the advantages of adherence to medication and clinic attendance as well as life style modifications including individualized dietary and exercise instructions (e.g., involvement in aerobic exercise, reduced alcohol and salt intakes, etc.). Brisk walking was specially demonstrated to patients in the intervention group at least 4 times during the study period. All of the patients received phone calls a week before their clinic visit days and a day before each actual visit day. At least 4 sessions of such interventions were held with each patient. The control group was deprived of the intervention strategies, except for the usual phone call reminders for appointment days.

\section{HRQOL Instrument}

RAND 36-Item Health Survey (version 1.0) questionnaire [14] was used to assess HRQOL of the patients. The questionnaire tests 8 areas, i.e., physical function, bodily pain, role limitations arising from physical health issues, and role limitations as a result of emotional problems. Others include emotional well-being, social functioning, and energy/fatigue, as well as perceptions arising from general health. It also includes a single item that provides an indication of perceived changes in health. Scoring the RAND 36-Item Health Survey is a 2-step process. First, precoded numeric values are recoded as per the given scoring key. All items are scored so that a high score defines a more favorable health state. In addition, each item is scored on a scale of $0-100$ so that the lowest and highest possible scores are set at 0 and 100, respectively. Scores represent the percentage of the total possible score achieved. In step 2, items in the same scale are averaged together to create the 8 scale scores.

\section{Inclusion Criteria}

Outpatients with a diagnosis of type 2 diabetes mellitus who had been on hypoglycemic medication(s) for more than 3 months, 
received medical care from the hospital for diabetes, signed the consent form, and were at least 50 years old during the study period were enrolled.

\section{Exclusion Criteria}

Patients with mental incompetence, acute illness, and comorbidities other than hypertension and those who declined participation were excluded. Patients were free to withdraw from this study upon expression of such willingness, but none withdrew.

Outcome Measure

The outcome measure was changes in adherence level and HRQOL domains.

\section{Data Analysis}

Responses to questionnaires and other data collected were coded and entered into Microsoft Excel for sorting, and Statistical Package for Social Sciences (SPSS) software version 16 (SPSS Inc., Chicago, IL, USA) was used for further analysis. Data were analyzed using descriptive and comparative analyses. $\chi^{2}$ and Fisher's exact tests were used for comparison of proportions, while Student's $t$ test was used for comparison of means as appropriate. A subanalysis was performed to determine possible relationship between variables. At $95 \% \mathrm{CI}, p \leq 0.05$ was considered statistically significant. Results are presented as means and percents.

\section{Results}

A total of 170 eligible consenting patients participated in this study. Female subjects were more frequent than male subjects, with approximate female-to-male ratios of 10:7 and 11:6 in the control and intervention groups, respectively. The majority of the patients ( 42.7 and $46.7 \%$, respectively) in both groups had a primary level of education, and the majority (70.6\%) lived on an average monthly income of less than NGN 5,000-20,000. The socio-demographic characteristics of the 2 groups showed no statistical significant differences (Table 1).

Impact of the Number and Dosage Frequency of Drugs on Adherence

Patients were asked whether the number of medicines and the dosage frequency affected their adherence. Those who answered "yes" and "no complaints," respectively, were recorded. At the baseline, 58.8 and $64.7 \%$ of the patients in the control and intervention groups said "yes" (indicating a negative effect on their adherence) to taking $>5$ drugs per prescription, while the figures changed to 55.3 and $15.3 \% 8$ months after the interventions ( $p=$ 0.711 and $p=0.000$, respectively). The rates of those who responded "yes" to a dosage frequency of $>1$ per day at baseline were 69.4 and $57.6 \%$ for the control and intervention groups $(p=0.463)$, while the postintervention
Table 1. Sociodemographic characteristics of the study patients

\begin{tabular}{|c|c|c|c|}
\hline Variable & $\begin{array}{l}\text { Control } \\
\text { patients }\end{array}$ & $\begin{array}{l}\text { Intervention } \\
\text { patients }\end{array}$ & $\begin{array}{l}p \\
\text { value }\end{array}$ \\
\hline $\begin{array}{l}\text { Respondents, } n \\
\text { Gender }\end{array}$ & 85 & 85 & \\
\hline Male & $35(41.2)$ & $32(37.6)$ & 0.754 \\
\hline Female & $50(58.8)$ & $53(62.4)$ & \\
\hline \multicolumn{4}{|l|}{ Age (years) } \\
\hline $50-69$ & $52(61.2)$ & $57(67.1)$ & 0.523 \\
\hline$>69$ & $33(38.8)$ & $28(32.9)$ & \\
\hline \multicolumn{4}{|l|}{ Marital status } \\
\hline Single & $3(3.5)$ & $6(7.1)$ & \\
\hline Married & $59(69.4)$ & $54(63.5)$ & 0.521 \\
\hline $\begin{array}{l}\text { Widow/widower/divorced } \\
\text { Level of education }\end{array}$ & $23(27.1)$ & $25(29.4)$ & \\
\hline None to secondary & $77(90.6)$ & $72(84.7)$ & 0.352 \\
\hline Tertiary and above & $8(9.4)$ & $13(15.3)$ & \\
\hline \multicolumn{4}{|l|}{ Occupation } \\
\hline \multicolumn{4}{|l|}{$\begin{array}{l}\text { Top civil servant, health } \\
\text { professional, business }\end{array}$} \\
\hline person, etc. & $62(72.9)$ & $65(76.5)$ & \\
\hline $\begin{array}{l}\text { Retired, farmer, or other } \\
\text { Average monthly income } \\
(\mathrm{NGN})\end{array}$ & $23(27.1)$ & $20(23.5)$ & 0.725 \\
\hline$<5,000-20,000$ & $60(70.6)$ & $68(80.0)$ & \\
\hline $21,000>30,000$ & $25(29.4)$ & $17(20.0)$ & 0.213 \\
\hline
\end{tabular}

Values are presented as numbers (\%) unless otherwise stated.

values were 65.9 and $12.9 \%$, respectively $(p<0.000)$. There were no statistically significant changes recorded 4 months into the intervention, although this is not presented in Table 2.

Influence of Pill Burden on the HRQOL Scores of Patients at Baseline and at 4 and 8 Months (Control)

Patients on 1-5 pills per prescription had no significant improved HRQOL scores in any of the domains at 4 and 8 months compared to baseline $(p>0.05)$. Physical functioning scores were: baseline $(44.2 \pm 14.2)$ versus 4 months $(47.2 \pm 19.1)$ and 8 months $(47.7 \pm 16.1) ; p=$ 0.277 and $p=0.160$. General health scores were: baseline $(53.8 \pm 5.4)$ versus 4 months $(50.2 \pm 16.1)$ and 8 months (54.0 \pm 13.3$) ; p=0.068$ and $p=0.904$ (Table 3a).

\section{Influence of Pill Burden on the HRQOL Scores}

of Patients at Baseline and 4 and 8 Months

(Intervention)

Those on 1-5 pills per prescription had extremely significant higher HRQOL scores $(p<0.001)$ in all domains except for pain $(p>0.05)$ at 4 and 8 months. Physical 
Table 2. Impact of the number and dosage frequency of drugs on adherence

\begin{tabular}{|c|c|c|c|c|c|c|}
\hline \multirow[t]{2}{*}{ Variable } & \multicolumn{3}{|c|}{ Baseline ( $n=85$ each) } & \multicolumn{3}{|c|}{8 months ( $n=85$ each $)$} \\
\hline & control & intervention & $p$ value & control & intervention & $p$ value \\
\hline \multicolumn{7}{|c|}{ Drugs per prescription ( $n$ ) } \\
\hline $1-5^{\circ}$ & $20(23.5)$ & $18(21.2)$ & 0.858 & $16(18.8)$ & $5(5.9)$ & 0.035 \\
\hline$>5$ & $50(58.8)$ & $55(64.7)$ & 0.711 & $47(55.3)$ & $13(15.3)$ & 0.000 \\
\hline No complaints & $15(17.6)$ & $12(14.1)$ & 0.680 & $22(25.9)$ & $67(78.8)$ & 0.000 \\
\hline \multicolumn{7}{|c|}{ Dosage frequency $(n)$} \\
\hline$>1$ & $59(69.4)$ & $49(57.6)$ & 0.463 & $56(65.9)$ & $11(12.9)$ & $<0.000$ \\
\hline No complaints & $17(20.0)$ & $23(27.1)$ & 0.482 & $20(23.5)$ & $73(85.9)$ & $<0.000$ \\
\hline
\end{tabular}

Values are presented as numbers (\%).

Table 3. Influence of 1-5 pills on the HRQOL scores of patients at baseline and 4 and 8 months

\begin{tabular}{lllll}
\hline Domains & Baseline $^{\mathrm{a}}$ & 4 months $^{\mathrm{b}}$ & 8 months $^{\mathrm{c}}$ & $p$ value \\
\hline a 1-5 pills (control group) & & & & \\
Physical functioning & $44.2 \pm 14.2$ & $47.2 \pm 19.1$ & $47.7 \pm 16.1$ & $0.277^{\mathrm{ab}}, 0.160^{\mathrm{ac}}$ \\
Role limitations due to PH & $26.6 \pm 11.1$ & $24.2 \pm 11.4$ & $31.3 \pm 26.3$ & $0.194^{\mathrm{ab}}, 0.156^{\mathrm{ac}}$ \\
Role limitations due to EP & $22.5 \pm 18.2$ & $23.4 \pm 16.2$ & $28.0 \pm 23.3$ & $0.750^{\mathrm{ab}}, 0.109^{\mathrm{ac}}$ \\
Energy/fatigue & $33.6 \pm 15.9$ & $36.4 \pm 16.5$ & $37.3 \pm 24.1$ & $0.292^{\mathrm{ab}}, 0.269^{\mathrm{ac}}$ \\
Emotional well-being & $29.5 \pm 9.5$ & $29.2 \pm 14.2$ & $32.0 \pm 11.1$ & $0.879^{\mathrm{ab}}, 0.141^{\mathrm{ac}}$ \\
Social functioning & $43.5 \pm 6.6$ & $42.1 \pm 17.5$ & $39.3 \pm 22.7$ & $0.518^{\mathrm{ab}}, 0.126^{\mathrm{ac}}$ \\
Pain & $51.1 \pm 14.4$ & $47.3 \pm 18.2$ & $51.8 \pm 18.1$ & $0.158^{\mathrm{ab}}, 0.794^{\mathrm{ac}}$ \\
General health & $53.8 \pm 5.4$ & $50.2 \pm 16.1$ & $54.0 \pm 13.3$ & $0.068^{\mathrm{ab}}, 0.904^{\mathrm{ac}}$ \\
\hline b 1-5 pills (intervention group) & & & & \\
Physical functioning & $41.7 \pm 16.1$ & $67.6 \pm 23.1$ & $92.5 \pm 3.5$ & $<0.000^{\mathrm{ab}, \mathrm{ac}}$ \\
Role limitations due to PH & $25.0 \pm 13.3$ & $54.2 \pm 12.8$ & $91.5 \pm 28.2$ & $<0.000^{\mathrm{ab}, \mathrm{ac}}$ \\
Role limitations due to EP & $22.2 \pm 14.4$ & $53.4 \pm 13.6$ & $90.0 \pm 21.4$ & $<0.000^{\mathrm{ab}, \mathrm{ac}}$ \\
Energy/fatigue & $31.3 \pm 8.7$ & $50.4 \pm 10.0$ & $60.0 \pm 14.1$ & $<0.000^{\mathrm{ab}, \mathrm{ac}}$ \\
Emotional well-being & $30.0 \pm 10.0$ & $48.2 \pm 12.4$ & $60.0 \pm 14.1$ & $<0.000^{\mathrm{ab}, \mathrm{ac}}$ \\
Social functioning & $41.7 \pm 7.2$ & $52.1 \pm 11.7$ & $81.3 \pm 26.5$ & $<0.000^{\mathrm{ab}, \mathrm{ac}}$ \\
Pain & $50.8 \pm 11.5$ & $53.9 \pm 22.1$ & $55.7 \pm 23.8$ & $0.283^{\mathrm{ab}}, 0.111^{\mathrm{ac}}$ \\
General health & $56.7 \pm 5.8$ & $66.6 \pm 18.6$ & $77.5 \pm 10.6$ & $<0.000^{\mathrm{ab}, \mathrm{ac}}$
\end{tabular}

Values are presented as means \pm SD. PH, physical health; EP, emotional problems.

functioning scores were: baseline $(41.7 \pm 16.1)$ versus 4 months (67.6 \pm 23.1$)$ and 8 months $(92.5 \pm 3.5) ; p \leq 0.001$. Pain scores were: baseline $(50.8 \pm 11.5)$ versus 4 months $(53.9 \pm 22.1)$ and 8 months $(55.7 \pm 23.8) ; p=0.283$ and $p=0.111$ (Table $3 b)$.

\section{Influence of $>5$ Pills on the HRQOL Scores of Patients at Baseline and 4 and 8 Months (Control)}

Patients in the control group with $>5$ pills per prescription had no significant improved HRQOL scores in any of the domains at 4 and 8 months compared to baseline
( $p>0.05)$. Physical functioning scores were: baseline $(53.2 \pm 17.8)$ versus 4 months $(52.2 \pm 9.6)$ and 8 months $(56.5 \pm 11.1) ; p=0.669$ and $p=0.175$. General health scores were: baseline $(60.5 \pm 17.7)$ versus 4 months (58.3 $\pm 19.2)$ and 8 months $(60.8 \pm 9.6) ; p=0.467$ and $p=0.898$ (Table 4a).

Influence of $>5$ Pills on the HRQOL Scores of Patients at Baseline and 4 and 8 Months (Intervention)

Those patients on $>5$ pills per prescription had significant higher HRQOL scores $(p<0.05)$ in 5 domains at 4 
Table 4. Influence of $>5$ pills on the HRQOL scores of patients at baseline and 4 and 8 months

\begin{tabular}{|c|c|c|c|c|}
\hline Domains & Baseline $^{\mathrm{a}}$ & 4 months ${ }^{b}$ & 8 months $^{c}$ & $p$ value \\
\hline \multicolumn{5}{|l|}{ a $>5$ pills (control group) } \\
\hline Physical functioning & $53.2 \pm 17.8$ & $52.2 \pm 9.6$ & $56.5 \pm 11.1$ & $0.669^{\mathrm{ab}}, 0.175^{\mathrm{ac}}$ \\
\hline Role limitations due to $\mathrm{PH}$ & $34.3 \pm 37.7$ & $36.9 \pm 31.7$ & $35.1 \pm 21.2$ & $0.648^{\mathrm{ab}}, 0.873^{\mathrm{ac}}$ \\
\hline Role limitations due to EP & $36.1 \pm 38.0$ & $35.0 \pm 34.2$ & $37.3 \pm 23.8$ & $0.852^{\mathrm{ab},} 0.817^{\mathrm{ac}}$ \\
\hline Energy/fatigue & $36.9 \pm 12.8$ & $38.1 \pm 12.2$ & $37.4 \pm 7.8$ & $0.558^{\mathrm{ab}}, 0.773^{\mathrm{ac}}$ \\
\hline Emotional well-being & $40.6 \pm 6.7$ & $37.7 \pm 13.3$ & $38.4 \pm 8.4$ & $0.094^{\mathrm{ab}}, 0.078^{\mathrm{ac}}$ \\
\hline Social functioning & $51.2 \pm 22.2$ & $51.9 \pm 13.5$ & $50.1 \pm 11.6$ & $0.816^{\mathrm{ab}}, 0.704^{\mathrm{ac}}$ \\
\hline Pain & $44.2 \pm 21.9$ & $42.8 \pm 23.3$ & $41.4 \pm 18.9$ & $0.705^{\mathrm{ab}}, 0.403^{\mathrm{ac}}$ \\
\hline General health & $60.5 \pm 17.7$ & $58.3 \pm 19.2$ & $60.8 \pm 9.6$ & $0.467^{\mathrm{ab}}, 0.898^{\mathrm{ac}}$ \\
\hline \multicolumn{5}{|l|}{ b >5 pills (intervention group) } \\
\hline Physical functioning & $57.0 \pm 19.8$ & $63.6 \pm 18.8$ & $75.7 \pm 14.2$ & $0.038^{\mathrm{ab}},<0.000^{\mathrm{ac}}$ \\
\hline Role limitations due to $\mathrm{PH}$ & $33.3 \pm 41.9$ & $46.7 \pm 39.7$ & $83.5 \pm 23.5$ & $0.046^{\mathrm{ab}},<0.000^{\mathrm{ac}}$ \\
\hline Role limitations due to EP & $33.3 \pm 45.4$ & $48.3 \pm 46.2$ & $87.8 \pm 33.1$ & $0.047^{\mathrm{ab}},<0.000^{\mathrm{ac}}$ \\
\hline Energy/fatigue & $32.8 \pm 12.8$ & $50.9 \pm 11.7$ & $55.4 \pm 8.0$ & $<0.000^{\mathrm{ab}, \mathrm{ac}}$ \\
\hline Emotional well-being & $37.3 \pm 11.5$ & $42.7 \pm 11.5$ & $62.8 \pm 7.6$ & $0.005^{\mathrm{ab}},<0.000^{\mathrm{ac}}$ \\
\hline Social functioning & $56.2 \pm 19.4$ & $60.8 \pm 21.6$ & $65.2 \pm 16.4$ & $0.172^{\mathrm{ab}}, 0.003^{\mathrm{ac}}$ \\
\hline Pain & $61.5 \pm 25.1$ & $66.2 \pm 26.9$ & $62.4 \pm 20.9$ & $0.270^{\mathrm{ab}}, 0.812^{\mathrm{ac}}$ \\
\hline General health & $61.0 \pm 19.1$ & $61.8 \pm 21.3$ & $67.8 \pm 12.8$ & $0.809^{\mathrm{ab}}, 0.011^{\mathrm{ac}}$ \\
\hline
\end{tabular}

Values are presented as means $\pm \mathrm{SD}$. PH, physical health; EP, emotional problems.

months and in 7 domains at 8 months, except for the pain domain, which was not affected by the intervention $(p>$ $0.05)$. Physical functioning scores were: baseline (57.0 \pm $19.8)$ versus 4 months $(63.6 \pm 18.8)$ and 8 months $(75.7 \pm$ $14.2) ; p=0.038$ and $p<0.001$. General health scores were: baseline $(61.0 \pm 19.1)$ versus 4 months $(61.8 \pm 21.3)$ and 8 months $(67.8 \pm 12.8) ; p=0.809$ and $p=0.011$ (Table $4 \mathrm{~b}$ ).

\section{Discussion}

The number of drugs and the dosage frequency were some of the factors found in this study that impacted negatively on the patients' health through a reduction of adherence to medications, which could have led to a poor HRQOL. A study [15] reported that patients might experience adverse side effects as treatment regimens become more complex, while some earlier researchers $[11,12]$ found that patients became less likely to adhere to their medications. According to a study [16], medication adherence contributes to an improved quality of life among type 2 diabetic patients. This study shows that the poor baseline HRQOL in all domains of the diabetic patients improved after the first and second interventions, with the exception of the pain domain, across board. This is consistent with a previous study [17], where significant improvement in HRQOL after 1-4 months of treatment with antiretroviral therapy was reported and the improvement persisted until 12 months. Another work also recorded significant improvement in all domains after 6 months of interventions on the HRQOL of hypertensive patients [18]. This result is indicative of more pills and less improvement in HRQOL, and this is consistent with the findings of a study [19] which revealed that the higher the number of medications was, the lower the HRQOL scores were. A large number of medications may impact negatively on the HRQOL domains, which could be a resultant effect of a poor adherence leading to worse therapeutic outcomes. This was seen in the baseline values of the control and intervention groups of this study. These results may not be unexpected as patients requiring more medications are likely to have an increased severity of disease and therefore this points to the need for health care providers who manage diabetes and other chronic diseases to pay particular attention to the quality of life of this group of patients. Patients taking a small number of tablets that are probably packed in small containers may experience fewer side effects. Patients on a single daily dose have been found to enjoy greater improvements in HRQOL overall [20]. A pill burden reduction can be achieved if unnecessary drugs are removed from the patient's prescribed list of drugs when deemed necessary. This is a way of saving for the patient. Previous studies have found that interventions by clinical pharmacists are able to reduce costs $[21,22]$. In this study, a pill 
burden reduction was not employed through medication removal from the prescription list.

The improvement in the overall HRQOL can be attributed to the increased numbers of times that the pharmacist met with the patients as well as adoption of an individualized lifestyle modification strategy with a special focus on exercise and diet. Individualized exercise is of great importance as it has been found that increasing daily movement could lower postprandial hyperglycemia and improve the management of blood glucose in diabetic patients $[23,24]$. The adoption of individualized dietary instruction has also been found to be necessary for the management of type 2 diabetes and to reduce the development of complications [25]. All of these adoptions of new life style modifications paid off, resulting in success of the intervention.

\section{Conclusion}

The burden arising from medication use is high in diabetic patients as they may be saddled with more drugs to address some comorbidities such as hypertension, arthritis, hyperlipidemia, etc. All of these make it difficult for such patients to be adherent, leading to poor HRQOL outcomes. This study demonstrates the pharmacist's ability to improve the HRQOL of patients following continuous counselling, supply of relevant information, and monitoring of drug, exercise, and diet adherence. Interventions such as this could be of great benefit to diabetic patients and others suffering from chronic diseases.

\section{Acknowledgement}

The author would like to thank the hospital management for granting the ethical approval, as well as the research assistants and the study participants for their time and cooperation.

\section{Statement of Ethics}

Ethical approval to carry out this research and to administer questionnaires to the patients was sought and obtained from the hospital's ethics review committee before the commencement of this study. The patient informed consent form was designed by the researcher and approved by the ethical committee for use in the study.

\section{Funding Sources}

This study was self-funded.

\section{Disclosure Statement}

The author has no conflict of interests to declare.

\section{References}

1 International Diabetes Federation. IDF Diabetes Atlas. 8th ed. Basel, Switzerland: International Diabetes Federation; 2017.

2 Brown AF, Mangione CM, Saliba D, Sarkisian CA. California Healthcare Foundation/ American Geriatrics Society Panel on Improving Care for Elders with Diabetes. Guidelines for improving the care of the older person with diabetes mellitus. J Am Geriatr Soc. 2003;51:S265-80.

3 American Diabetes Association. Standards of medical care in diabetes. J Clin Appl Res Educ. 2017;40:1-142.

4 American Diabetes Association. Diagnosis and classification of diabetes mellitus. Diabetes Care. 2014;37:S81-90.

5 Gebremedhin T, Workicho A, Angaw DA. Health-related quality of life and its associated factors among adult patients with type II diabetes attending Mizan Tepi University Teaching Hospital, Southwest Ethiopia. BMJ Open Diabetes Res Care. 2019;7(1):e000577.

6 Ababio GK, Bosomprah S, Olumide A, Aperkor N, Aimakhu C, Oteng-Yeboah A, et al. Predictors of quality of life in patients with diabetes mellitus in two tertiary health insti- tutions in Ghana and Nigeria. Niger Postgrad Med J. 2017;24(1):48-55.

7 International Diabetes Federation. IDF Diabetes Atlas. Basel: International Diabetic Federation; 2015.

8 Sue Kirkman M, Briscoe VJ, Clark N, Florez H, Haas LB, Halter JB, et al. Diabetes in older adults: a consensus report. J Am Geriatr Soc. 2012;60(12):2342-56.

9 Odegard PS, Capoccia K. Medication taking and diabetes: a systematic review of the literature. Diabetes Educ. 2007;33(6):1014-29.

10 Piette JD, Heisler M, Wagner TH. Problems paying out-of-pocket medication costs among older adults with diabetes. Diabetes Care. 2004;27(2):384-91.

11 Martin LR, Williams SL, Haskard KB, et al. The challenge of patient adherence. Ther Clin Risk Manag. 2005;1:189-99.

12 Donnan PT, MacDonald TM, Morris AD. Adherence to prescribed oral hypoglycaemic medication in a population of patients with Type 2 diabetes: a retrospective cohort study. Diabet Med. 2002;19(4):279-84.

13 World Health Organization. Definition of an old or older person: health statistics and health information systems. (World Health Survey). Geneva: WHO; 2009.

14 Hays RD, Sherbourne CD, Mazel RM. The RAND 36-Item Health Survey 1.0. Health Econ. 1993;2(3):217-27.

15 Pollack MF, Purayidathil FW, Bolge SC, Williams SA. Patient-reported tolerability issues with oral antidiabetic agents: associations with adherence; treatment satisfaction and health-related quality of life. Diabetes Res Clin Pract. 2010;87(2):204-10.

16 Alfian SD, Sukandar H, Lestari K. Medication adherence contributes to an improved QOL T2DM patients. Diabetes Ther. 2016;7:75564.

17 Mannheimer SB, Matts J, Telzak E, Chesney M, Child C, Wu AW, et al.; Beirn Community Programs for Clinical Research on AIDS Quality of life in HIV-infected individuals receiving antiretroviral therapy is related to adherence. AIDS Care. 2005;17(1):10-22.

18 Shahina PT, Revikumar KG, Krishnan R, Jaleel VA, Shini VK. Impact of pharmacist interventions on quality of life in patients with hypertension. Int J Pharm Sci Rev Res. 2010; 5(3):172-6 
19 Jennings DL, Ragucci KR, Chumney EC, Wessell AM. Impact of clinical pharmacist intervention on diabetes related quality of life in an ambulatory care clinic. Pharm Pract (Granada). 2007;5(4):169-73.

20 Jackson KA. Comparison of single tablet once daily therapeutic options for the treatment of HIV/AIDS. Residency Pharmacotherapy Conference 2012.
21 Kopp BJ, Mrsan M, Erstad BL, Duby JJ. Cost implications of and potential adverse events prevented by interventions of a critical care pharmacist. Am J Health Syst Pharm. 2007; 64(23):2483-7.

22 Schumock GT, Meek PD, Ploetz PA, Vermeulen LC. Economic evaluations of clinical pharmacy services: 1988-1995. Pharmacotherapy. 1996;16(6):1188-208.

23 Henson J, Davies MJ, Bodicoat DH, Edwardson CL, Gill JM, Stensel DJ, et al. Breaking up prolonged sitting with standing or walking attenuates the postprandial metabolic response in postmenopausal women: a randomized acute study. Diabetes Care. 2016;39(1):130-8.
24 Dempsey PC, Larsen RN, Sethi P, Sacre JW, Straznicky NE, Cohen ND, et al. Benefits for type 2 diabetes of interrupting prolonged sitting with brief bouts of light walking or simple resistance activities. Diabetes Care. 2016; 39(6):964-72.

25 American Diabetes Association. Nutrition recommendations and interventions for diabetes: a position statement of the American Diabetes Association. Diabetes Care. 2008; 31:S61-78. 